https://doi.org/10.22319/rmcp.v11i3.5798

Artículo

\title{
Indicadores de competitividad de la carne bovina de México en el mercado mundial
}

Miguel Ángel Magaña Magaña ${ }^{b}$

Carlos Enrique Leyva Morales ${ }^{\text {a* }}$

Juan Felipe Alonzo Solís ${ }^{\text {a }}$

Carlos Gabriel Leyva Pech ${ }^{a}$

${ }^{a}$ Universidad Autónoma de Yucatán. Facultad de Economía. Km 1 carretera Mérida-Tizimin, Cholul, Yucatán, México.

b Tecnológico Nacional de México/Instituto Tecnológico de Conkal. Conkal, Yucatán, México.

Autor de correspondencia: clmoral@ correo.uady.mx

\section{Resumen:}

El presente trabajo tiene por finalidad evaluar la posición y tendencia de la competitividad de la carne bovina en canal de México frente a la oferta externa, como la relación entre esta ventaja mercantil, la producción y la exportación nacional, que permitan proponer estrategias que potencialicen la ganadería en el mediano plazo. Para lograr este objetivo se calcularon cuatro indicadores de competitividad tomando en cuenta el procedimiento postulado por el Instituto Interamericano de Cooperación para la Agricultura, y el grado de asociación entre variables se determinó con el coeficiente de Pearson. El volumen de oferta primaria de carne bovina posiciona a México en el séptimo lugar mundial, mientras que como exportador se coloca en el quinceavo puesto; se halló que la exportación del país de este cárnico tiene como destino mayoritario el mercado de los Estados Unidos de América, y que la producción nacional presenta un bajo nivel de competitividad en el mercado internacional. En el comportamiento de la producción y exportación de la carne bovina mexicana influyen factores que se vinculan con las características del mercado y del proceso comercial, así como 
con fenómenos naturales, los cuales determinan tanto la productividad, como la generación de saldos exportables de carne en canal y de valor para la economía del país.

Palabras clave: Competitividad, Exportación, Ganadería bovina, Carne en canal.

Recibido: 22/08/2018

Aceptado: 05/07/2019

\section{Introducción}

Desde la perspectiva macroeconómica, la competitividad es la capacidad de un sector productivo, como el de la ganadería bovina de carne en canal de México, para enfrentar la competencia mundial $^{(1)}$, esto implica que pueda vender en los mercados externos, que tenga la cualidad y eficiencia tanto para producir y mantener niveles crecientes de ganancias de sus recursos, así como minimizar el efecto de las importaciones. Así, la inclusión y duración de un producto en el mercado mundial dependen de su nivel de competitividad, en el que intervienen factores como la productividad y características del producto ${ }^{(2)}$, movimientos de la tasa de cambio $^{(3)}$, disponibilidad de infraestructura para la comercialización y la dotación de factores productivos con bajos costos relativos ${ }^{(4)}$.

De acuerdo con $\mathrm{FAO}^{(5)}$, en 2014 la producción mundial de carne bovina fue de 64.7 millones de toneladas, de los cuales Estados Unidos concentró el $17.7 \%$, le siguen Brasil (15.0 \%), China (10.2\%), Argentina (4.13\%) y Australia (4\%). En el citado año, México fue el sexto productor de esta carne, participando con $2.8 \%$; en el comercio exterior, en 2013 ocupó el quinceavo lugar en exportación. Por otra parte, los principales países importadores de carne bovina en 2013 fueron Italia con 257.9 mil t, seguido por Países Bajos (214.1 mil t), Alemania (141 mil t), Francia (120.9 mil t) y China (104.2 mil t).

La evolución del mercado mundial de la carne bovina y la competitividad que presentan los países participantes en éste, ejercen una influencia sobre la dinámica de la ganadería bovina de México, con lo cual se tienen repercusiones positivas o negativas, dependiendo del nivel de su competitividad. Lo anterior es relevante debido a que la ganadería es una actividad de importancia económica y, dentro de ésta, la producción de carne es la más productiva y practicada en todo el país; debido a que proporciona importantes materias primas, divisas y empleos, que se traducen en un mayor bienestar social de la población. Así lo evidencian las estadísticas correspondientes, las cuales muestran que de 1990 al 2000 el volumen de la producción y exportación de este cárnico exhibieron en lo general un comportamiento en 
sentido opuesto; la primera creció en $26.5 \%$ mientras que la segunda decayó $5.9 \%$; para el período 2001 a 2013 la producción creció $(25.1 \%)$ al igual que la exportación $(6,928.2 \%)$ de manera muy significativa ${ }^{(5,6)}$.

La situación descrita, trajo consecuencias benéficas en el subsector pecuario y en la economía nacional. Entre éstas destacan su efecto sobre el nivel de ingresos que se generan en poco más de un millón de unidades productoras; la creación de 1.1 millones de empleos directos y de 3 millones en forma indirecta ${ }^{(7)} y$, en la producción de carne bovina superior a los 24 mil millones de dólares. Esta última cifra representó el $23.70 \%$ del valor de la producción pecuaria nacional del año $2013^{(6)}$.

Sin embargo, bajo el contexto anterior, la competitividad de la carne bovina de México en el mercado mundial, se refleja en la oferta exportable de sólo 0.8 \% de la producción (20002013), mientras que el volumen de importaciones representó el $0.7 \%$ del consumo nacional aparente. Estas participaciones evidencian que el mercado externo es pequeño, pero el superávit de la balanza comercial indica que existen condiciones favorables para mejorar la posición de México; por ello, y para contribuir a la escasa información respecto a este tema, el presente trabajo plantea evaluar la posición y tendencia de la competitividad que presenta la carne bovina en canal mexicana frente a la oferta externa de los países productores más importantes, como la relación que se establece entre esta ventaja mercantil, la producción y la exportación, que permitan proponer estrategias de acción que potencialicen la actividad ganadera en el mediano plazo.

\section{Material y métodos}

El método general que se utilizó fue el deductivo de corte longitudinal de tendencia, y basado en parámetros estimados de información indirecta; la principal fuente fue el $\operatorname{FAOSTAT}^{(5)} \mathrm{y}$ la complementaria el SIACON ${ }^{(6)}$. Los parámetros de interés, por su nivel de alcance y cobertura, son los considerados como indicadores de resultado o ex post ${ }^{(8)}$, ya que permiten el análisis del comportamiento de un producto final proveniente de los eslabones de una cadena productiva en relación con los respectivos productos de los competidores extranjeros, esto, tanto en los mercados internos como externo.

La medición del nivel de competitividad se llevó a cabo mediante cuatro índices cuyo cálculo se realizó con base en los procedimientos propuestos por el Instituto Interamericano de Cooperación para la Agricultura (IICA), en tanto que los parámetros complementarios, de carácter descriptivo o correlacional entre variables, se estimaron de acuerdo con Levin y Rubin $^{(9)}$. Los índices de interés se describen a continuación: 
1. Indicador de Transabilidad (IT). Este mide la relación entre la balanza comercial neta y el consumo nacional aparente (CNA) de un país, es decir la participación de las exportaciones o las importaciones en el consumo de un producto. Su fórmula de cálculo:

$\mathrm{Tij}=(\mathrm{Xij}-\mathrm{Mij}) /(\mathrm{Qij}+\mathrm{Mij}-\mathrm{Xij})$

Donde: $\mathrm{Xij}=$ exportaciones del producto i del país j;

Mij = importaciones del producto i del país j;

Qij = producción del bien i en el país j.

Este índice tiene dos indicadores auxiliares: el grado de apertura exportadora y el grado de penetración de importaciones.

2. Indicador de Balanza Comercial Relativa (IBCR). Mide el balance comercial entre países respecto al mismo bien, y permite establecer el grado de ventaja o desventaja comparativa existente. Fue propuesto por Bela Balassa como variante del Índice de GrubellLloyd $^{(10)}$. Algebraicamente se representa como:

$\mathrm{BCR}=(\mathrm{Xij}-\mathrm{Mij}) /(\mathrm{Xij}+\mathrm{Mij})$,

Donde: $\mathrm{Xij}=$ Exportaciones de un producto i por un país j al mercado mundial;

Mij = Importaciones de un producto i por un país j al mercado mundial. Refleja ventaja competitiva cuando es positivo y desventaja cuando es negativo.

3. Especialización Internacional o de Lafay (EI). Este mide la relación entre la balanza comercial neta y las exportaciones mundiales de un producto, permite evaluar la vocación exportadora y la capacidad que tiene un país para construir ventajas competitivas permanentes. Se calcula mediante la siguiente expresión:

$\mathrm{IE}=(\mathrm{Xij}-\mathrm{Mij}) / \mathrm{Xim}$

Donde: Xim $=$ Exportaciones del bien i realizadas por el mundo. Cuando este índice vale uno o 100\%, el país es el único exportador, pero si es negativo no presenta algún grado de especialización y tiene dificultades competitivas.

4. Ventaja Comparativa Revelada (VCR). Este índice compara la eficiencia en el uso de los recursos en el tiempo tanto para la producción como para el consumo de todos los bienes de un país, revelada por su flujo comercial y donde es más eficiente aquel con el menor costo de oportunidad ${ }^{(11)}$. Representa el resultado de la asignación de éstos en la economía y refleja su posición de especialización en el mercado. Se expresa como:

$\operatorname{VCR}^{i}{ }_{a}=\operatorname{VCE}_{a}^{i}-\operatorname{VCI}_{a}^{i}$

Donde: $\mathrm{VCE}=$ ventaja comparativa revelada de las exportaciones;

$\mathrm{VCI}=$ ventaja comparativa revelada de las importaciones.

Estos componentes de la VCR se calcularon mediante las ecuaciones:

$$
\begin{aligned}
& \operatorname{VCE}_{\mathrm{a}}^{\mathrm{i}}=\operatorname{In}\left[\left(\mathrm{X}_{\mathrm{a}}^{\mathrm{i}} / \mathrm{X}_{\mathrm{n}}^{\mathrm{i}}\right) /\left(\mathrm{X}_{\mathrm{a}}^{\mathrm{r}} / \mathrm{X}_{\mathrm{n}}^{\mathrm{r}}\right)\right] \\
& \operatorname{VCI}^{\mathrm{i}}{ }_{\mathrm{a}}=\operatorname{In}\left[\left(\mathrm{M}_{\mathrm{a}}^{\mathrm{i}} / \mathrm{M}_{\mathrm{n}}^{\mathrm{i}}\right) /\left(\mathrm{M}_{\mathrm{a}}^{\mathrm{r}} / \mathrm{M}_{\mathrm{n}}^{\mathrm{r}}\right)\right]
\end{aligned}
$$

Las letras X y M expresan el valor de las exportaciones e importaciones; el subíndice (n) es el valor del comercio de todas las mercancías de todos los sectores menos el producto de interés (a); el superíndice (r) alude al valor del comercio del mundo menos el del país de referencia (i) y la expresión (ln) indica el logaritmo natural. Los posibles resultados en el VCR dependen del valor combinado del VCI y el VCE y son: 
1. $\mathrm{VCE}>0, \mathrm{VCI}<0$; VCR $>0$. El país muestra ventaja comparativa en exportaciones de un producto y desventaja comparativa en importaciones, lo que resulta en un VCR positivo.

2. $\mathrm{VCE}>0, \mathrm{VCI}>0 ; \mathrm{VCR}>\mathrm{o}<0$. Existen ventajas comparativas en la exportación e importación, el VCR será mayor o menor que cero si VCE es mayor o menor que el VCI.

3. $\mathrm{VCE}<0, \mathrm{VCI}>0$; $\mathrm{VCR}<0$. El país muestra desventaja comparativa en la exportación y ventaja comparativa en la importación, y el VCR es negativo.

4. $\mathrm{VCE}<0, \mathrm{VCI}<0 ; \mathrm{VCR}<0$. Evidencia desventaja comparativa tanto en la exportación como en la importación de un producto, y el VCR puede ser positivo o negativo. El significado del VCR es ambiguo y puede conducir a errores de interpretación, por ejemplo un valor positivo indica que el país no interviene en forma significativa en el comercio mundial de exportaciones o importaciones ${ }^{(12)}$.

\section{Resultados}

\section{Producción y balanza comercial mexicana de carne bovina}

El volumen de producción de la carne bovina en canal en México presenta una tendencia general hacia la alza de 1990 a 2013 (Figura 1), su crecimiento fue del $62.2 \%$, y pasó de 1,114 a 1,806.8 mil toneladas, con un volumen promedio anual de $1,554.6$ mil toneladas ${ }^{(6)}$. Sin embargo, el nivel de rendimiento de carne en canal por animal $(204.7 \mathrm{~kg}$ en el período 2004-2013) ubicó al país en el lugar 69 en productividad. 
Figura 1: Producción y exportación de carne bovina de México

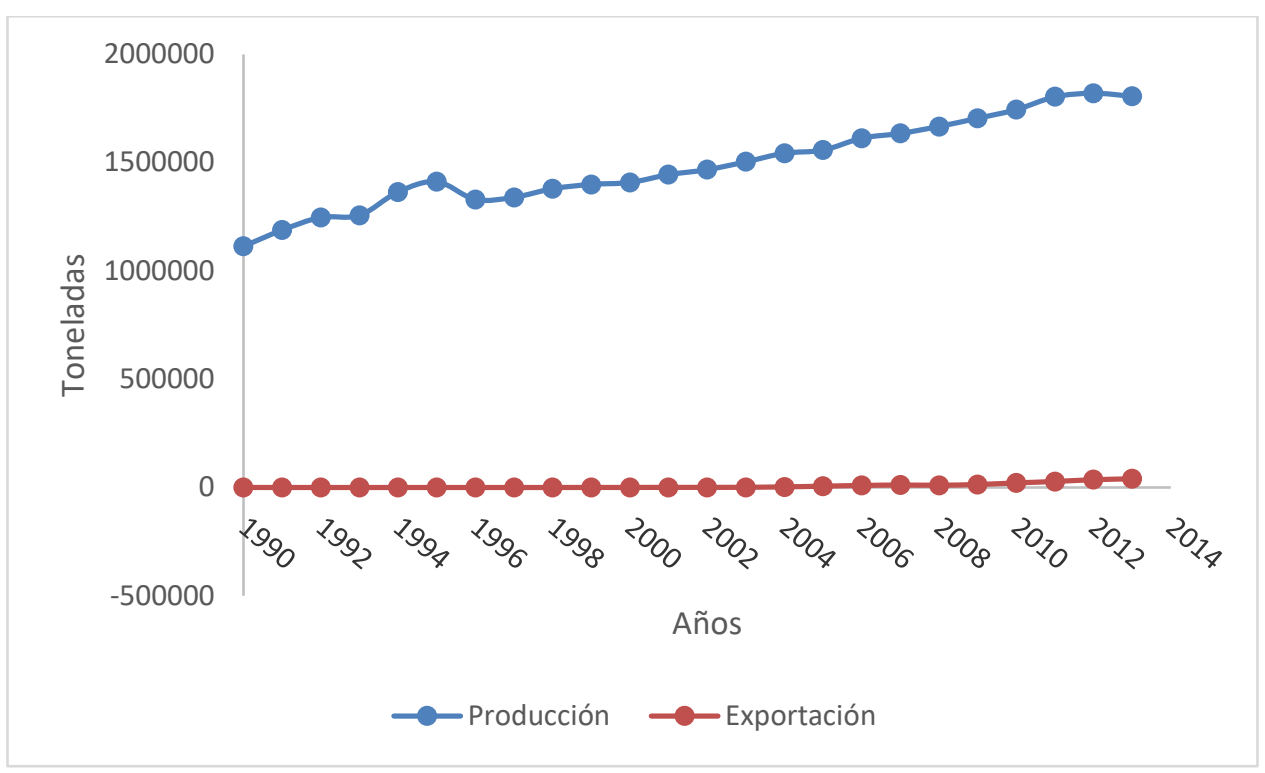

En el mercado mundial, el país se caracterizó por ocupar el quinceavo lugar como exportador de esta carne en el citado período, Polonia encabeza esta lista; en tanto en el continente americano se posicionó en el segundo puesto. El volumen promedio anual de las exportaciones mexicanas fue de 17.9 mil toneladas y representó el $1.2 \%$ de la producción nacional. Esta cifra representó un avance notable, dado que en el primer quinquenio de la década de los noventa éste era casi inexistente, del $0.004 \%{ }^{(5,6)}$. La participación promedio de la oferta exportable de México al mercado mundial de carne bovina en el período 2004-2013 fue del $1.1 \% \mathrm{y}$, con respecto al continente americano, ésta fue del $10 \%$. Cabe mencionar que la región de América sólo aporta el $11.1 \%$ de la exportación mundial de esta carne, la cual es liderada por la zona de Europa $(80.1 \%)$.

Los principales destinos de la oferta exportable de carne bovina en canal de México en el año $2013^{(5)}$, fueron los Estados Unidos de Norteamérica (95.5\%), Vietnam (2.7 \%) y Japón $(0.6 \%)$. En tanto que, en 2004, Estados Unidos captó el $87.5 \%$ de esta exportación, y la República de Corea (12\%) fue el otro destino de importancia. El primer país citado es el principal importador de esta carne en el mundo, y hacia él se canalizó en promedio el $97 \%$ del total de las exportaciones nacionales en el período de estudio.

En lo que respecta a la balanza comercial de la carne bovina en México del 2004 al 2013, el volumen de las exportaciones fue ascendente y creció $37.1 \%$, las importaciones también crecieron (58.9 \%); pero al ser mayor el volumen de las exportaciones en relación con las importaciones, la balanza fue superavitaria (promedio anual de 23.9 mil t). Sin embargo, la mayor dinámica de las importaciones evidencia la existencia de una pérdida de competitividad de la ganadería bovina nacional, y porque el tratado de libre comercio con 
Estados Unidos dejó al país en desventaja en cuanto a competitividad, ya que dicho país es el mayor productor y exportador de carne bovina en el mundo.

\section{Indicadores de competitividad}

\section{Índice de transabilidad}

Este índice evidencia que de 139 países productores de carne bovina Polonia ocupa la primera posición competitiva (Cuadro 1), ya que presentó la mayor relación entre su balanza comercial neta y el respectivo consumo aparente de dicha carne. Este nivel de competitividad es acorde con su nivel de apertura exportadora y su ínfima penetración de importaciones; el citado país exporta casi el $40 \%$ de su producción, mientras que este parámetro fue de 0.5 , 0.1 y 0.2 \% para Estados Unidos, Brasil y Argentina, respectivamente. Lo anterior permite inferir que los principales países productores mantienen una baja relación entre su exportación y producción de carne bovina, y también afirmar que sin importar el nivel de desarrollo del país la exportación es relativamente baja con respecto a su producción nacional.

Cuadro 1: Indicador de transabilidad de la carne bovina en el mercado mundial 2004-2013

\begin{tabular}{|c|c|c|c|c|c|}
\hline P a ís & $\begin{array}{c}\text { Indicador } \\
\text { de trans. } \\
(\%) \\
\end{array}$ & $\begin{array}{c}\text { Posición } \\
\text { competiv. }\end{array}$ & Característica & $\begin{array}{c}\text { Apertura } \\
\text { exportadora } \\
(\%)\end{array}$ & $\begin{array}{c}\text { Penetración } \\
\text { de import. } \\
(\%)\end{array}$ \\
\hline Estados Unidos & 0.20 & 19 & Exceso de oferta & 0.54 & 0.34 \\
\hline Brasil & 0.00 & 29 & $\begin{array}{l}\text { Exceso de } \\
\text { demanda }\end{array}$ & 0.05 & 0.05 \\
\hline China & -0.31 & 39 & $\begin{array}{l}\text { Exceso de } \\
\text { demanda }\end{array}$ & 0.03 & 0.34 \\
\hline Argentina & 0.15 & 21 & Exceso de oferta & 0.20 & 0.06 \\
\hline Australia & 2.65 & 12 & Exceso de oferta & 2.66 & 0.02 \\
\hline Federación de Rusia & -10.10 & 48 & $\begin{array}{l}\text { Exceso de } \\
\text { demanda }\end{array}$ & 0.00 & 10.10 \\
\hline México & 0.79 & 17 & Exceso de oferta & 1.07 & 0.28 \\
\hline Francia & 3.54 & 11 & Exceso de oferta & 12.19 & 8.65 \\
\hline Canadá & 1.54 & 15 & Exceso de oferta & 2.44 & 0.90 \\
\hline Alemania & 10.19 & 5 & Exceso de oferta & 18.94 & 8.75 \\
\hline Polonia & 64.22 & 1 & Exceso de oferta & 65.22 & 1.00 \\
\hline
\end{tabular}

Fuente: Elaboración propia con base en datos de FAOSTAT. 
Por otra parte, la disponibilidad de excedentes de exportación de Polonia representa aproximadamente el 0.7 del volumen de su consumo nacional aparente de carne bovina, muy superior al registrado para los Estados Unidos, Brasil, Argentina y Australia. El contraste se tiene con Italia, el onceavo país productor de importancia de esta carne en el mundo, pero también es un importador significativo. El IT de Italia muestra un exceso de demanda del $18.6 \%$ de su consumo nacional aparente (CNA), que se satisface con volúmenes procedentes de varios países; su grado de penetración de importaciones $(22.01 \%)$, le otorga una baja posición competitiva de su producción interna.

De acuerdo con el IT, México ocupa el $17^{\circ}$ lugar en competitividad; sus exportaciones de carne en canal de ganado bovino representan un poco más del $1 \%$ de su CNA, en tanto que las importaciones representan menos de una centésima de esta variable. Estos valores evidencian, como para la mayoría de países en desarrollo, que más que exhibir capacidad exportadora, lo que tienen son recursos naturales para esta producción (pastizales y vegetación natural), un bajo nivel de ingreso per cápita ${ }^{(13)}$ y una limitada preferencia por esta carne $^{(14)}$, lo que en conjunto genera los excedentes exportables.

Una situación a destacar en el mercado mundial de la carne bovina es el de la India, cuyo indicador de transabilidad (1.1\%) lo sitúa en el lugar 16 en competitividad. Sin embargo, se distingue de otros países exportadores, porque: primero, no importa esta carne y su producción interna satisface el $101 \%$ de su CNA; segundo, su hato ganadero es superado sólo por el de los Estados Unidos; tercero, más de 800 millones profesan el hinduismo que prohíbe el sacrificio de vacas (animal sagrado), por lo que su industria procesadora de carne se enfoca a la exportación; y, cuarto, ofrece un producto de bajo precio, que abastece mercados poco exigentes en cuanto a calidad (casi $40 \%$ inferior al de Brasil); características con las que ha conquistado mercados del sudeste asiático y medio oriente ${ }^{(15)}$; rasgos que no poseen países en desarrollo, como Argentina y México.

\section{Indicador de balanza comercial relativa}

Los países que presentaron mayor ventaja en el mercado internacional de la carne bovina con este índice fueron India y Vietnam, cuyos valores fueron $100 \%$ (Cuadro 2); siguió en importancia Colombia (99.9\%), y las posiciones siguientes le correspondió a Uruguay $(99.8 \%)$ y Paraguay $(99.7 \%)$. 
Cuadro 2: Balanza comercial relativa (BCR) de la carne bovina mexicana

\begin{tabular}{lllll}
\hline \multicolumn{1}{c}{ P a í s } & $\begin{array}{l}\text { Indicador } \\
\text { de BCR } \\
(\boldsymbol{\%})\end{array}$ & $\begin{array}{l}\text { Posición } \\
\text { competiv. }\end{array}$ & Característica & $\begin{array}{l}\text { Saldo neto } \\
\text { Bal. comercial } \\
(\boldsymbol{\%})\end{array}$ \\
\hline Estados Unidos & 22.24 & 25 & Ventaja & 229,701 \\
Brasil & -1.21 & 29 & Desventaja & $-1,107$ \\
China & -85.02 & 37 & Desventaja & $-184,151$ \\
Argentina & 55.75 & 18 & Ventaja & 43,050 \\
Australia & 98.85 & 7 & Ventaja & 552,522 \\
Federación de Rusia & -99.93 & 46 & Desventaja & $-1940,720$ \\
México & 58.03 & 17 & Ventaja & 131,702 \\
Francia & 16.97 & 26 & Ventaja & 515,858 \\
Canadá & 46.09 & 23 & Ventaja & 194,312 \\
Alemania & 36.78 & 24 & Ventaja & 1092,780 \\
Italia & -72.97 & 33 & Desventaja & $-2383,357$ \\
\hline
\end{tabular}

Fuente: Elaboración propia con base en datos de FAOSTAT.

La posición competitiva de México en el mundo con base a este indicador (58.03\%), se mantiene en la misma que le confirió el IT, el lugar diecisiete. La producción de carne bovina mexicana se caracteriza porque su oferta externa rebasa su demanda y por lo tanto se cuenta con excedentes para exportar; sin embargo, es superado por varios países de América como Brasil y Argentina, que presentan mejor ventaja competitiva.

Es relevante señalar que, de los países productores de importancia, sólo Estados Unidos presentó un BCR favorable durante el período analizado (22.2 \%), que lo ubica en el lugar 25. En contraste Brasil, China y la Federación de Rusia, al registrar saldos deficitarios en su balanza comercial y al presentar un BCR de $-1.2,-85.0$ y $-99.9 \%$, respectivamente, demuestran una condición clara de desventaja en el mercado. De estas tres naciones, sólo China incrementó su déficit comercial, cuyo saldo pasó de 7,409 t de carne bovina en 2004 a 102,285 t en 2013; un incremento del 1,280.6\%. Por su parte, la Federación de Rusia redujo su déficit comercial, su balanza pasó de $-184,363$ t en 2004 a $-92,807$ en 2013; un decremento del $49.7 \%$. En tanto Brasil superó su déficit comercial a partir del año 2012, ya que el saldo de su balanza paso de -743 t en 2004 a un superávit de 5,695 en 2013.

\section{Indicador de Especialización Internacional o de Lafay}

La información contenida en el Cuadro 3, confirma que Polonia y Alemania poseen la más alta especialización comercial y competencia en el mercado mundial de la carne bovina en 
canal, cuyos índices en el período 2004-2013 fueron de 96.9 y $72.9 \%$, respectivamente; demostrando así su capacidad para construir ventajas competitivas en este mercado.

Cuadro 3: Especialización internacional en el mercado de la carne bovina 2004-2013

\begin{tabular}{lllll}
\hline \multicolumn{1}{c}{ P a í s } & $\begin{array}{l}\text { Indicador } \\
\text { de espec. } \\
(\boldsymbol{\%})\end{array}$ & $\begin{array}{l}\text { Posición } \\
\text { competiv. }\end{array}$ & Característica & $\begin{array}{l}\text { Participación } \\
\text { export. mundo } \\
(\boldsymbol{\%})\end{array}$ \\
\hline Estados Unidos & 1.53 & 13 & Bajo & 4.21 \\
Brasil & -0.01 & 35 & Bajo & 0.30 \\
China & -1.23 & 43 & Bajo & 0.11 \\
Argentina & 0.29 & 19 & Bajo & 0.40 \\
Australia & 3.69 & 5 & Intermedio & 3.71 \\
Federación Rusa & -12.95 & 49 & Bajo & 0.00 \\
México & 0.88 & 16 & Bajo & 1.20 \\
Francia & 3.44 & 6 & Bajo & 11.87 \\
Canadá & 1.30 & 14 & Bajo & 2.06 \\
Alemania & 7.29 & 2 & Alto & 13.56 \\
Italia & -15.91 & 50 & Bajo & 2.95 \\
\hline
\end{tabular}

Fuente: Elaboración propia con base en datos de FAOSTAT.

Resulta significativo destacar que, de acuerdo al índice EI, Australia es el único país que presenta una competitividad de nivel intermedio en el mercado, en tanto la Federación de Rusia (-12.9\%) e Italia (-15.9\%), que integran el conjunto de principales países productores de este cárnico, no registraron grado de especialización alguno. México en este contexto se situó en el lugar 16 mundial, con una competitividad considerada como baja ( $0.9 \%)$. Los dos indicadores de competitividad previos y este último, confirman la posición competitiva de México en el mercado de la carne bovina, la cual no resulta ideal para un país con bastos recursos naturales y con una actividad ganadera generalizada en todo su territorio; esto presupone una limitada productividad por superficie y por vientre, así como por un bajo rendimiento en canal por animal finalizado ${ }^{(6)}$.

\section{Índice de ventaja comparativa revelada}

El indicador de VCR (Cuadro 4), constata que Australia es el país cuya oferta externa de carne bovina posee el más alto nivel de competitividad desde el punto de vista del costo de oportunidad de sus recursos productivos; su indicador promedió fue de 6.0 durante 20042013 y, en general, presentó una tendencia creciente; este valor fue superior al de México (1.7), que se ubicó en el segundo lugar. Argentina ocupó el tercer puesto (1.1), mientras que 
Estados Unidos fue el cuarto (0.9). Brasil, China y la Federación Rusa, con presencia relevante en el mercado mundial, por el valor de su VCR, y el de sus índices de transabilidad y de especialización internacional, presentaron falta de competitividad en dicho mercado.

Cuadro 4: Ventaja comparativa revelada por país productor de carne bovina 2004-2013

\begin{tabular}{lllllllllll}
\hline \multirow{2}{*}{ País } & \multicolumn{8}{c}{ Indicador de ventaja comparativa revelada } \\
\cline { 2 - 11 } & $\mathbf{2 0 0 4}$ & $\mathbf{2 0 0 5}$ & $\mathbf{2 0 0 6}$ & $\mathbf{2 0 0 7}$ & $\mathbf{2 0 0 8}$ & $\mathbf{2 0 0 9}$ & $\mathbf{2 0 1 0}$ & $\mathbf{2 0 1 1}$ & $\mathbf{2 0 1 2}$ & $\mathbf{2 0 1 3}$ \\
\hline E.U.A & -0.40 & -0.15 & 0.35 & 0.63 & 1.48 & 1.22 & 1.33 & 1.35 & 1.16 & 1.50 \\
Brasil & -0.73 & -1.12 & -0.51 & -0.66 & -0.17 & -0.68 & -0.42 & -0.67 & -0.01 & 0.59 \\
China & -2.75 & -2.76 & -1.91 & -2.21 & -2.58 & -2.02 & -2.47 & -2.72 & -2.67 & -4.20 \\
Argentina & 1.16 & 1.21 & 1.44 & 0.68 & 1.38 & 2.08 & 0.45 & 1.34 & -0.10 & 0 \\
Australia & 5.62 & 6.32 & 6.39 & 7.23 & 6.54 & 5.84 & 5.40 & 4.95 & 5.26 & 6.12 \\
Fed.Rusa & -8.85 & -12.93 & 0 & 0 & -10.84 & 0 & -12.02 & -8.99 & -5.74 & -6.03 \\
Francia & 0.42 & 0.46 & 0.68 & 0.74 & 0.85 & 0.88 & 0.96 & 1.18 & 0.73 & 0.61 \\
México & 2.36 & 2.57 & 1.51 & 1.02 & 0.53 & 1.14 & 1.60 & 1.87 & 2.06 & 2.08 \\
Alemania & 1.43 & 1.15 & 1.26 & 0.88 & 0.88 & 0.78 & 0.63 & 0.43 & 0.12 & 0.04 \\
Canadá & 1.77 & 1.24 & 0.62 & 0.36 & -0.03 & 0.22 & 0.68 & 0.18 & -0.05 & 0.04 \\
Italia & -3.04 & -2.93 & -2.76 & -2.56 & -2.48 & -2.69 & -2.50 & -2.30 & -2.45 & -2.46 \\
\hline
\end{tabular}

Fuente: Elaboración propia con base en datos de FAOSTAT.

De acuerdo al principio de la ventaja comparativa ${ }^{(16)}$, el óptimo económico se alcanza cuando un país produce y exporta aquellos bienes para los cuales tiene ventaja e importa los que muestran desventaja, lo cual explica la asignación de recursos en los tres países antes citados. De acuerdo a esta lógica, si se pretende establecer empresas productivas con menor costo de oportunidad, el exportar menos o importar la carne bovina les reditúa un mayor beneficio económico, entonces esto confirma la estructura de las relaciones de intercambio por país productor, como ocurre en China, donde la producción industrial interna resulta de mayor importancia económica que la producción primaria.

Asimismo, se comprueba que sólo dos países de América Latina, México y Argentina, registran niveles positivos de competitividad; a pesar de que en ambos casos el VCR presentó ligera tendencia hacia la baja con marcados altibajos (Figura 2), pero el rango de variación de Argentina resultó ligeramente mayor al de México. El VCR para Argentina se redujo en 2.1 puntos y su coeficiente de variación (CV) fue de $71.6 \%$, en tanto que para México éste osciló en 2.0 puntos y su CV fue de $38.1 \%$. En contraste, dicho índice para Estados Unidos y Australia se caracterizó por su mayor estabilidad, ya que su variación fue de 1.6 puntos $(\mathrm{CV}=82.5 \%)$ y $1.4(\mathrm{CV}=60.8 \%)$, respectivamente. 
Figura 2: Indicadores de ventaja comparativa revelada

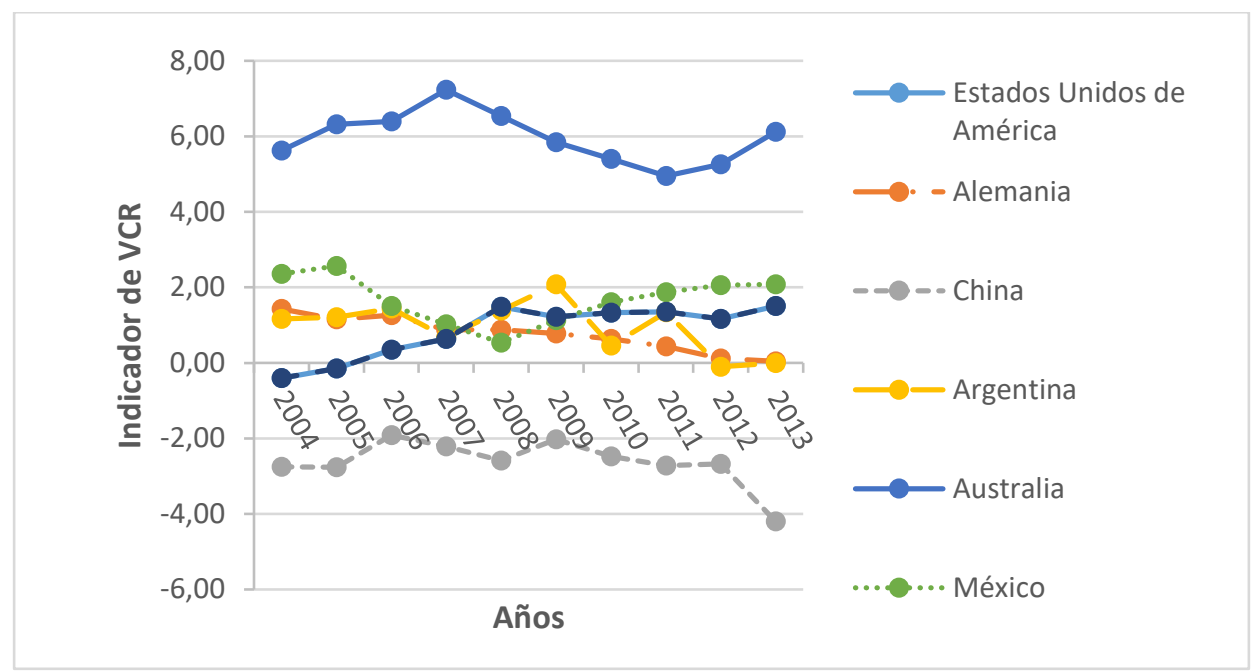

Es importante señalar que en la mayoría de los años de 2004 a 2013, los coeficientes VCR de Argentina y México registraron un valor mayor a la unidad, que evidencia un mejor desempeño del subsector ganadero bovino de carne, estos en realidad resultaron ambiguos, dado que sus VCE fueron menores que cero en la mayor parte de los años, al igual que sus VCI, lo cual se interpreta que ambos tienen desventaja comparativa tanto en exportación como en importación, por lo que no intervienen significativamente en el comercio mundial de la carne bovina. Esto no se presenta para Australia y Alemania, que muestran ventaja comparativa en exportaciones y desventaja en importaciones, tal y como lo indica el criterio de análisis presentado en la metodología.

Con base en lo expuesto, se infiere que México por su VCE negativo de 2004 a 2011, muestra desventaja comparativa en la producción de carne bovina, con tendencia a su reducción, pero se vuelve positivo en 2012 y 2013. Este comportamiento por componente del VCR significa que paulatinamente el país fue adquiriendo mayor nivel de competitividad. Las importaciones de carne bovina de 2004 al 2008, fueron acordes a la lógica del costo de oportunidad de disponibilidad de un producto; la producción nacional fue menos eficiente en términos de precio o de calidad que la de otros países, y por ello la importación se volvió una mejor alternativa para la economía.

Por último, la relación que se establece entre los volúmenes de exportación de la carne bovina de México y el valor del índice VCE, y la que se da entre el índice de VCR y la oferta interna de carne bovina de 2004-2013, la primera fue acorde a los principios de la lógica económica del comercio internacional (Figura 3), en donde el coeficiente de correlación ( $r=0.92)$ evidencia que existe una asociación alta y en el mismo sentido de variación entre la citada variable y el indicador de ventaja correspondiente. Con respecto a la segunda relación, ésta 
presentó un coeficiente de correlación negativo ( $\mathrm{r}=-0.09$ ), lo cual revela que al incrementarse el nivel de competitividad del país en este mercado se reduce en términos relativos su oferta interna de carne bovina, esto último se observa en el comportamiento de sus exportaciones, las cuales en el período variaron a una mayor tasa promedio $(37.1 \%)$ que los respectivos volúmenes de carne producidos $(1.8 \%)$.

Figura 3: Relación entre ventas externas de carne bovina y la ventaja comparativa de exportación de México

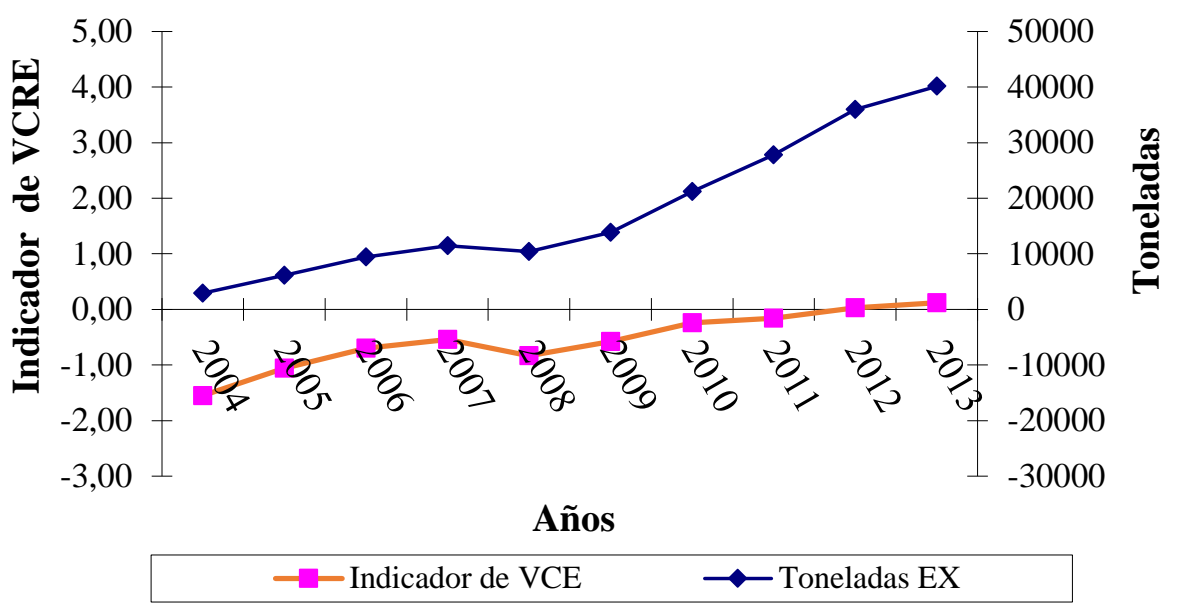

\section{Discusión}

Es importante mencionar que sobre la calidad y diferenciación de la carne bovina producida en México, como sobre su rendimiento en canal, variables relacionadas con la producción y competitividad de las exportaciones, han influido diversos factores económicos en su comportamiento de largo plazo, entre estos destacan la firma e inicio del TLCAN en 1994(15), y los problemas de carácter estructural de la política económica aplicada por el gobierno federal $^{(17)}$ a partir del año 1982, los cuales se han reflejado en aspectos puntuales de esta actividad productiva, tales como: la pérdida de rentabilidad y competitividad (en costos y precios de venta), la desaparición de unidades de producción y en la pérdida de empleos; durante este proceso de transición de una actividad protegida a su inserción al libre mercado. En años posteriores, la ganadería nacional ha presentado una recuperación al impacto negativo del fenómeno anterior.

En cuanto a la competitividad de la carne bovina en el mercado internacional, el análisis del IT permitió constatar que no todos los países que destacan como productores son a su vez los 
principales exportadores, un claro ejemplo de esta situación es Italia, cuyo IT la sitúa en el lugar 49 en competitividad, cuando en realidad, y por su capacidad comercial, fue el onceavo exportador de carne bovina de 2004 al 2013. En este contexto, y de acuerdo con el índice de especialización internacional, la carne bovina de México se caracterizó por presentar un bajo nivel de ventaja competitiva, así como poca vocación exportadora, situación que coincide con lo reportado para el país de 1980 a $2009^{(18)}$ y, en forma comparativa, con lo reportado por Depetris $e t a l^{(19)}$ del desempeño competitivo de la producción de leche en polvo de Argentina y Uruguay durante 1990-2005.

El citado grado de competitividad de México podría mejorarse con incrementos en la calidad y la diferenciación de la carne bovina, dado que la exportación de ésta se da en la forma de carne fresca, refrigerada y congelada, pero el patrón de preferencias de los consumidores de los países importadores se orienta hacia los cortes selectos, contenido de grasa veteada, grado de terneza y tipo de carne ${ }^{(15,17)}$. En respuesta a esta exigencia en la actividad ganadera nacional se han estado sustituyendo razas bovinas tradicionales por mejoradas, según exigencia del mercado; el rendimiento en canal creció en promedio $0.2 \%$ al año de 1995 a 2014, bajo si se compara con el de Australia, donde este indicador creció $1.4 \%{ }^{(5)}$; aspecto relacionado con el costo medio de producción.

Por otra parte, del indicador de VCR, cuya relevancia considera la asignación de recursos productivos en la economía ${ }^{(16)}$, se infiere que éste para el mediano plazo presente un valor mayor que cero, un comportamiento ascendente y que no fluctúe en exceso, porque cuando ocurre esto último, como el caso de la carne bovina de México, es indicio de que la competitividad no está apoyada sobre una base económica fuerte, sino que más bien es producto de factores volátiles como: variación de la paridad cambiaria y la imposición de barreras no arancelarias a los países competidores, por lo que estas oportunidades sólo benefician las ventas al exterior de esta carne de manera eventual.

La situación anterior resulta consistente con lo reportado por Carrera y Bustamante ${ }^{(18)}$, quienes señalan que del año 1996 al 2003 la producción de carne de bovino de México registró baja competitividad en el mercado mundial, debido a que el indicador de la VCE resultó inferior al de la VCI, en el que el proceso de apertura comercial del país (TLCAN) fue el factor que empeoró la competitividad de la producción nacional. Asimismo, lo encontrado en el presente también coincide con los resultados de Carrera et al ${ }^{(17)}$ y Del Moral y Trujillo ${ }^{(20)}$; los primeros autores indican que la situación de la ganadería bovina mexicana reflejó en lo general una VCR negativa para el período de 1990 a 2009, aunque a partir de 2004 se recupera como respuesta a las restricciones en la importación de los Estados Unidos y Canadá a raíz de la enfermedad de EEB; mientras que los segundos autores evidenciaron que de 1980 a 2010, la producción de esta carne en el país se caracterizó por su desventaja comparativa revelada, reflejándose en la disminución de la producción de este cárnico y en el empeoramiento de su balanza comercial. 
Finalmente, el bajo grado de asociación encontrado entre el valor del indicador de VCR y la producción de carne bovina en México, se explica por las características del mercado y del proceso comercial. En primer lugar, en el país existe una deficiente infraestructura de comunicación y de comercialización ${ }^{(21)}$, creciente participación de las tiendas de autoservicio en la distribución de productos cárnicos, cuya oferta se compone por un elevado número de productos importados, que impactan negativamente a toda la cadena de valor de la carne bovina nacional. En segundo lugar, el margen bruto del proceso de comercialización resulta relativamente alto con relación al precio que se paga al ganadero, ya que apenas obtiene la cuarta parte del valor total generado, y quien no está organizado para enfrentar el poder de mercado que ejercen los mayoristas y detallistas; además, la carne bovina importada a bajos precios condiciona el precio que se paga al productor inicial, lo que tiene como consecuencia pérdida de rentabilidad.

La tercera característica de importancia en la citada asociación, es el deficiente acceso a los insumos alimenticios para el ganado, cuyos precios y calidad son desiguales respecto a Estados Unidos, como también lo son los subsidios que otorga el gobierno hacia esta actividad. La cuarta es la falta de integración y coordinación de la cadena productiva bovina, que se traduce en costos más elevados de producción, desaprovechamiento de economías de escala $^{(22)}$ y, por ende, menor competitividad de la cadena. La última característica, es la presencia de fenómenos naturales ${ }^{(20)}$, como inundaciones por eventos meteorológicos extremos y períodos prolongados de sequía, que han afectado la productividad de la carne bovina nacional y elevado su costo de producción.

\section{Conclusiones e implicaciones}

La carne de ganado bovino en canal de México se caracterizó en el ámbito mundial por su bajo nivel de competitividad durante el período 2004 al 2013, tal y como lo evidencian el valor de los índices de transabilidad, balanza comercial relativa, especialización internacional y los de ventaja comparativa revelada. Una característica de la exportación de esta carne es su único destino mayoritario, Estados Unidos de América. Asimismo, se demostró que, desde la década de los noventa, y como resultado de diversos sucesos económicos, la producción de carne bovina ha experimentado un crecimiento constante, aspecto que impactó positivamente la generación de saldos exportables; sin embargo, estos representan sólo una pequeña parte de la oferta primaria, acorde con la posición competitiva. La exportación de carne bovina no se sustenta en productos de calidad o en factores institucionales, sino es resultado de sucesos volátiles relacionados con el tipo de cambio e imposición a los países competidores de barreras no arancelarias. Dada las características de la producción de carne bovina nacional y su entorno macroeconómico, la consolidación de una mayor posición 
competitiva de la oferta exportable, que permita a los productores del país negociar los precios, requiere que se mejore tanto la calidad y la diferenciación de la carne bovina a través de la incorporación de valor agregado, el rendimiento de carne por animal y la disposición de infraestructura comercial, como de la apertura de nuevos mercados, condiciones que permitirían en el mediano plazo obtener un mejor nivel de competitividad y protagonismo en el mercado internacional de esta carne. Además, este escenario también permitiría acrecentar los impactos positivos que tiene la ganadería bovina en la economía y el bienestar regional del país.

\section{Literatura citada:}

1. Porter ME. Ventaja Competitiva. España: Editorial Pirámide; 2010.

2. Coronado F. Indicadores de productividad y competitividad regional relacionados al agro. CENTRUM Católica’s Working Paper. No. 2015-08-0010. Lima, Perú:

Pontificia Universidad Católica del Perú; 2015. http://vcentrum.pucp.edu.pe/investigacion/wps/pdf/CECYM_WP2015-08-0010.pdf.

3. Vázquez A, Reyes A. Fundamentos sobre la competitividad para el desarrollo en el sector primario. TLATEMOANI, Revista Académica de Investigación 2013;(4):1-29.

4. Gonzalez J, Zamora A, Celaya R, Navarro JC. Competitividad y logística del comercio exterior de México. Primera ed. Sonora, México: Instituto Tecnológico de Sonora y Universidad Michoacana de San Nicolás de Hidalgo; 2016.

5. FAOSTAT. Organización de las Naciones Unidas para la Agricultura y la Alimentación. Base de datos estadísticos con relación a la alimentación y agricultura. http://faostat.fao.org/site/535/DesktopDefault.aspx?PageID=535\#ancor. Consultado 16 Dic, 2015.

6. SIACON. Sistema de Información Agroalimentaria de Consulta. Base de datos de la actividad agrícola, pecuaria y pesquera en México. http://www.siap.gob.mx/optestadisticasiacon. Consultado 15 Dic, 2015.

7. AMEG. Carne de bovino. Indicadores económicos. 14 ed. México; 2012.

8. IICA. Instituto Interamericano de Cooperación para la Agricultura. Elementos para un enfoque de la competitividad en el sector agropecuario. Colección de documentos IICA. Serie competitividad No 3. Santa Fe de Bogotá, Colombia; 2000.

9. Levin R, Rubin D. Estadística para administración y economía. Séptima ed. México, DF: Pearson/Prentice Hall; 2004. 
10. Sierra SL, Peláez SJ. Amenazas comerciales del acuerdo CAN-Mercosur, para los sectores productivos del Valle del Cauca. Economía, Gestión y Desarrollo 2009;(7):47_ 62.

11. Cue M. Economía internacional. Primera ed. México: Grupo Editorial Patria; 2014.

12. Vollrath T. A theoretical evaluation of alternative trade intensity measures of revealed comparative advantage. Weltwirtschaftliches Archiv 1991;264-280.

13. CONEVAL. Comisión Nacional para la Evaluación de las Políticas de Desarrollo Social. Evolución de las carencias sociales 2015 y su comparativo con la serie 2010-2014. http://www.coneval.org.mx/Medicion/EDP/Paginas/Datos-del-Modulo-deCondiciones-Socioeconomicas.aspx. Consultado 15 Dic, 2015.

14. FIRA. Panorama agroalimentario: Carne de bovino 2015. México: Dirección de investigación y evaluación económica y sectorial; 2015.

15. Omaña JM, Almora I, Cruz B, Hoyos G, Quintero JM, Fortis M. Competitividad de la carne de ganado bovino entre los países miembros del TLCAN 1997-2008. Rev Mex Cienc Agr 2014;5(2):175-189.

16. Salvatore D. Economía internacional. Octava ed. México, DF: Ed. Limusa; 2005.

17. Carrera B, Gómez M, Schwentesius R. La ganadería bovina de carne en México: un recuento necesario después de la apertura comercial. Chihuahua, México: Universidad Autónoma de Ciudad Juárez; 2014.

18. Carrera ChB, Bustamante LT. ¿Es la ganadería bovina de carne una actividad competitiva en México? Noesis. Rev Cienc Soci Humanid 2013;22(43):19-50. http://www.redalyc.org/pdf/859/85927874002.pdf

19. Depetris GE, García AR, Rossini G. Desempeño competitivo de Argentina y Uruguay en la leche en polvo. Problemas del desarrollo 2009;40(157):163-187.

20. Del Moral L, Murillo VB. Dinámica del mercado de la carne bovina en México: un análisis de competitividad. Paradigma económico 2015;7(1):107-125.

21. Rodríguez D, Riveros H. Esquemas de comercialización que facilitan la vinculación de productores agrícolas. San José, Costa Rica: IICA; 2016.

22. Nicholson W. Teoría microeconómica. Novena imp. México, DF: Cengage Learning SA; 2008. 